Research Article

\title{
Experimental Study on the Microstructure and Expansion Characteristics of Paleosol Based on Spectral Scanning
}

\author{
Wanjun Ye, ${ }^{1}$ Yiqian Chen $\left(\mathbb{D},{ }^{1}\right.$ Chong Gao, ${ }^{2}$ Tengfei Xie, ${ }^{1}$ Hongjun Jing, \\ and Yousheng Deng ${ }^{1}$ \\ ${ }^{1}$ School of Architecture and Civil Engineering, Xi'an University of Science and Technology, Xi'an 710054, China \\ ${ }^{2}$ China Railway 19th Bureau Group Rail Transit Engineering Co.,Ltd., Beijing 101300, China \\ Correspondence should be addressed to Yiqian Chen; 18204054001@stu.xust.edu.cn
}

Received 22 October 2020; Revised 23 December 2020; Accepted 4 January 2021; Published 16 January 2021

Academic Editor: Paola Luches

Copyright (C) 2021 Wanjun Ye et al. This is an open access article distributed under the Creative Commons Attribution License, which permits unrestricted use, distribution, and reproduction in any medium, provided the original work is properly cited.

\begin{abstract}
To investigate the microstructure of paleosol and its expansion characteristics, the paleosol of the Zaosheng \#3 tunnel of the Yinxi high-speed railway was studied. Based on X-ray diffraction (XRD), energy-dispersive X-ray spectroscopy (EDX), nuclear magnetic resonance (NMR), and scanning electron microscopy techniques (SEM), the microstructure of the paleosol was analyzed in terms of the mineral composition, formation elements, pore structure, and particle morphology. Five groups of undisturbed and remolded soils with different moisture contents were tested for the unloaded expansion rate and loaded expansion rate. The results show that the mineral components of the paleosol are mainly quartz, potash feldspar, calcite, and hematite, with the highestcontent-component quartz accounting for $45.4 \%$ of the total content; the clay mineral composition of the paleosol has the highest content of montmorillonite at $12.3 \%$. The elemental composition of the paleosol is dominated by $\mathrm{Al}, \mathrm{Si}, \mathrm{Ca}$, and $\mathrm{Fe}$, which form expansive mineral components such as quartz and montmorillonite, creating inherent conditions for expansibility of the paleosol. The $T_{2}$ distribution curves of the undisturbed and remolded paleosol are composed of three peaks. The pore distribution of paleosol mainly includes medium pores, followed by large pores, and the contents of small pores and superlarge pores are very small. In terms of particle contact, the undisturbed soil is mostly in the form of "surface-surface" and "surface-edge" contact, and the remolded soil is mainly in the form of "point-surface" and "point-point" contact. The unloaded expansion rate of remolded soil is approximately twice that of undisturbed soil. The rate of loaded expansion of both soils decreases with increasing moisture content.
\end{abstract}

\section{Introduction}

In the 21st century, with the rapid development of China's economy, the construction of some large-scale geotechnical engineering projects has ushered in a new wave of development. One of the "ten longitudinal and ten transverse" integrated transport channels of China's " $13^{\text {th }}$ Five-Year Plan" modern integrated transportation network is the Yinxi high-speed rail (Yinchuan-Xi'an). Because it passes through a large area of expansive paleosol group, the project since its construction has attracted the attention of geotechnical experts. The expansive paleosol has both loess and expansive soil characteristics due to the special properties of the soil mass, which greatly affects the construction of the project. When the tunnel crosses the full section of the expansive paleosol, due to changes in the water content leading to the creation of floor heave arising from inverted arch deterioration, the support structure to withstand the expansion force must be enhanced, and under the restrictions of the support structure, serious deformation will occur, affecting construction safety. The understanding of the expansion properties of paleosols, which are not well studied, with studies mainly focused on paleosol genesis and mechanical strength, is insufficient. Feng et al. $[1,2]$ delineated the age of formation of paleosols and studied their parent soils. Zheng et al. $[3,4]$ explained the succession patterns of loess and paleosols in terms of soil mineral types, microstates, and spore composition. Moshe Wieder and Gvirtzman [5] found a rich calcareous layer in the paleosol of southern Israel by studying the paleosol. With regard to the mechanics of 
paleosols, Wan Jun et al. [6] studied the mechanical parameters and expansion characteristics of paleosols under dry and wet cycling in Qingyang, Gansu Province, and concluded that the unloaded expansion rate of paleosols showed a positive correlation with the number of dry and wet cycles. Wu Yuntao et al. [7] explored the deformation mechanism of paleosols under different stress paths by conducting triaxial shear tests and studied the changes in soil pores under different stress paths by nuclear magnetic resonance (NMR). Wang et al. [8] studied the shear strength of paleosols, and significant relaxation of soil stress was observed in cyclic load tests. In recent years, with the development of imaging technology, many microscopic testing techniques have been applied to quantitative analysis of soil microstructures to deepen the understanding of soil microscopic properties, including scanning electron microscopy (SEM), nuclear magnetic resonance (NMR), X-ray diffraction (XRD), and energy-dispersive $\mathrm{X}$-ray spectroscopy (EDX). At present, SEM technology is widely used in the microscopic study of clay [9], sand [10], loess [11], and other soils and has been applied to deep-sea soils [12-14] and lunar soils [15-17]. NMR technology, due to its advantages such as rapid and nondestructive detection, has recently been applied to quantitative study of fine-scale porosity aspects of rock and soil masses [18-22]. XRD can be used to analyze the crystal structure and mineral composition of soil masses based on the interference principle in optics [23, 24], and EDX can be used to study different constituent elements and their distribution in soil masses [25, 26], both of which are useful in the study of contaminated soils, with more applications in research.

In summary, research on paleosols mainly focuses on the genesis and mechanical behavior, and research on the expansibility is relatively rare. In addition, microscopic testing technology is widely used in soil pore identification, composition characterization, and other aspects. Many results are very instructive. However, most of them are studied in conjunction with soil mechanical parameters, and few studies on the exploration of paleosol expansibility from the microscopic aspect have been reported. In view of this, this article takes the paleosol of the Yinxi high-speed railway (HSR) Zaosheng \#3 tunnel as the research object. EDX, SEM, and NMR are used, and the results are combined with the existing research results of the author's research group on paleosol. The changes in the microstructure characteristics and expansion characteristics of the undisturbed and remolded soil samples are explored, and explanation of the expansion mechanism based on the elements, mineral components, and microstructure of the soil is attempted to provide a reference for paleosol engineering.

\section{Test Materials and Methods}

2.1. Basic Properties of the Sample. The soil samples were taken from the Zaosheng \#3 tunnel of the Yinxi HSR $($ DK187 + 245) (Figure 1). The soil samples were reddish brown, with a high clay content, a dense structure, a uniform texture, mainly hard plastic, calcium filaments and snail shells visible, and no obvious joints. The soil samples sealed with plastic wrap were sent to the laboratory, and the indoor test was carried out according to the relevant test procedures. The basic physical parameters of the samples were measured as shown in Table 1.

\subsection{Test Equipment}

2.2.1. Energy Spectrometer. The EDX instrument uses the new SU6600 thermal field scanning electron microscope (Figure 2(a)). The instrument is equipped with a variable pressure (VP) function and can be used to observe nonconductive samples without evaporation. The magnification can reach $60 \mathrm{w}$ times. For micronanomaterial fine morphological observations, the specific parameters are shown in Table 2.

2.2.2. NMR. The NMR scan was performed using an NMRC12-010V NMR pore analyzer (Figure 2(b)); the specific parameters are shown in Table 3. According to the low-field NMR principle, the hydrogen nucleus ${ }_{1} \mathrm{H}$ has only one proton with a small positive charge, a net magnetic moment, and angular momentum and is abundant in nature; thus, it is used as a good signal carrier. Under the action of an external magnetic field, the hydrogen nucleus ${ }_{1} \mathrm{H}$ is equivalent to a small magnetic needle, and the torque produced by the external magnetic field aligns the spin axis of the hydrogen nucleus with the magnetic field direction; the atomic nuclei in the magnetic field are arranged in one direction. According to the theory of quantum mechanics, when a hydrogen nucleus is in an external magnetic field, the protons are split into two energy states: high energy and low energy. The difference between the two states forms the magnetization vector $M_{0}$, which provides the measurement signal for NMR. The NMR relaxation measurement is usually used to express the measurement signal, which measures the porosity, pore size distribution, and other information about a porous medium.

Since the free relaxation and diffusion relaxation of soil pore fluids are relatively weak, the surface relaxation time, $T_{2}$, is usually used to study them. The expression is as follows:

$$
\frac{1}{T_{2}}=\rho_{2} \frac{S}{V}
$$

where $S$ is the pore surface area; $V$ is the pore volume; and $\rho_{2}$ is the relaxation rate of the dielectric surface, which is $4.0 \mu \mathrm{m} / \mathrm{s}$ for this calculation.

Assuming that the pore shape in the specimen is cylindrical, (1) simplifies to

$$
\frac{1}{T_{2}}=\rho_{2} \frac{2}{R}
$$

where $R$ is the pore radius. From the above formula, the pore radius $R$ is proportional to $T_{2}$; the lower the value of $T_{2}$ is, the smaller the pore radius is, and the higher the value of $T_{2}$ is, the larger the pore radius is. 


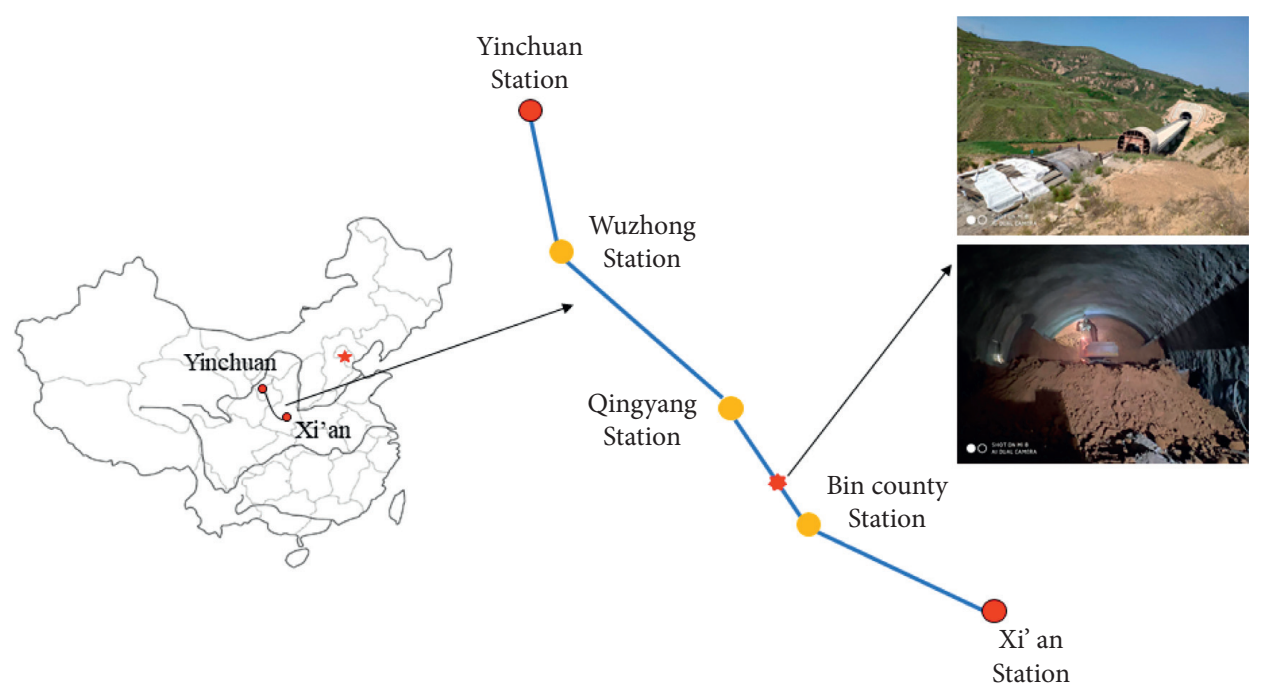

FIgURE 1: Map of Yinchuan-Xi'an high-speed railway.

TABLe 1: Average values of indicators of paleosol physical properties.

\begin{tabular}{lccccrr}
\hline$W$ & $W_{P}$ & $W_{L}$ & $I_{P}$ & $I_{L}$ & $\rho$ & $\rho_{d}$ \\
& & & & $\mathrm{~g} / \mathrm{cm}^{3}$ & \\
\hline 14.1 & 18.5 & 46.47 & 27.97 & -0.09 & 2.145 \\
\hline
\end{tabular}

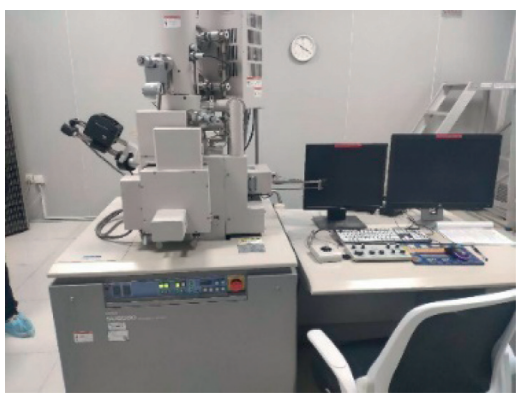

(a)

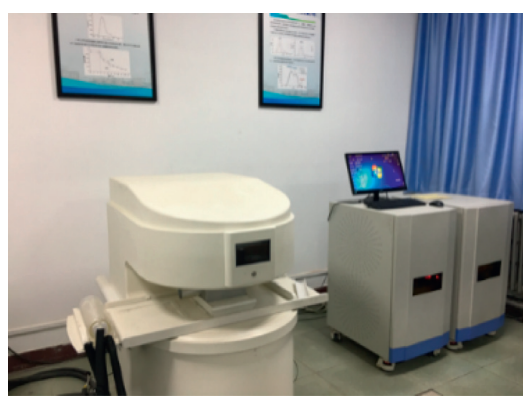

(b)

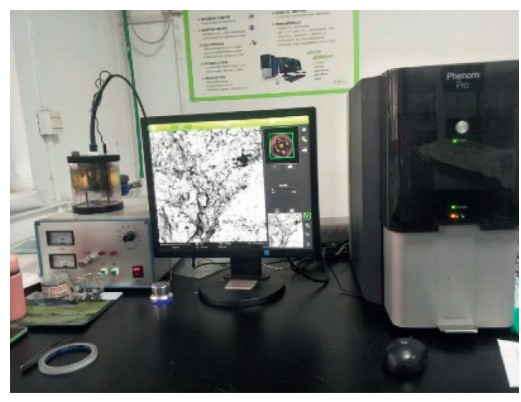

(c)

FIgURE 2: Test apparatus. (a) Spectroscopy. (b) NMR machine. (c) Scanning electron microscope.

TABLE 2: Spectrometer parameters.

\begin{tabular}{|c|c|c|c|}
\hline $\begin{array}{l}\text { SE resolution } \\
(\mathrm{nm})\end{array}$ & $\begin{array}{l}\text { BSE resolution } \\
(\mathrm{nm})\end{array}$ & Resolution & $\begin{array}{l}\text { Range of detected } \\
\text { elements }\end{array}$ \\
\hline 1.2 & 3.5 & $>125 \mathrm{eV}$ & Be4 Am95 \\
\hline
\end{tabular}

TABLE 3: NMR parameters.

\begin{tabular}{lcccc}
\hline $\begin{array}{l}\text { Magnet } \\
\text { type }\end{array}$ & $\begin{array}{c}\text { Magnetic } \\
\text { field } \\
\text { intensity }\end{array}$ & $\begin{array}{c}\text { Main } \\
\text { frequency } \\
\text { of } \\
\text { instrument } \\
(\mathrm{MHz})\end{array}$ & $\begin{array}{c}\text { Diameter } \\
\text { of probe } \\
\text { coil (mm) }\end{array}$ & $\begin{array}{c}\text { Variable } \\
\text { temperature } \\
\text { range }\end{array}$ \\
\hline $\begin{array}{l}\text { Permanent } \\
\text { magnet }\end{array}$ & $0.3 \pm 0.05 \mathrm{~T}$ & 12 & 10 & $-30^{\circ} \mathrm{C}-40^{\circ} \mathrm{C}$ \\
\hline
\end{tabular}

2.2.3. Electron Microscopy. A model Phenom/Pro benchtop scanning electron microscope made by Holland Fine was used. This instrument utilizes a backscatter detector and angular scattering imaging to provide most of the functions of conventional vertical SEM, with maximum magnification up to $130,000 \mathrm{x}$ and a high vacuum resolution of $3.0 \mathrm{~nm}$ to acquire clear microscopic images (Figure 2(c)).

2.3. Sample Preparation. Regarding the preparation of the undisturbed soil sample, in this experiment, the undisturbed soil samples were dried and then quantitatively humidified to prepare 5 groups of soil samples with different initial moisture contents. The soil sample retrieved from the site was cut into a ring-shaped sample $(61.8 \mathrm{~mm} \times 20 \mathrm{~mm})$ and dried in a drying oven for $24 \mathrm{~h}$. When the soil sample was dry, several small soil blocks were taken and dried at the same time, and then, the small soil blocks were removed with alcohol. The water content of the soil was determined by the combustion method several times, and finally, the water content of the small soil blocks after drying in the oven for $24 \mathrm{~h}$ was found to be between $2.4 \%$ and $3.1 \%$. The soil sample 
dried in the oven for $24 \mathrm{~h}$ was considered to have a moisture content of $3 \%$, and different moisture contents were prepared based on this moisture content. The main processes included drying-hydrating-standing and spreading.

Regarding the preparation of remolded samples, the retrieved soil samples were air-dried and crushed, passed through a $2 \mathrm{~mm}$ sieve, dried in a $105^{\circ} \mathrm{C}$ oven, and cooled to room temperature. The remolded soil was prepared at $10.1 \%$, $12.1 \%, 14.1 \%, 16.1 \%$, and $18.1 \%$ moisture contents, and the dry density of the remolded soil was set at $1.87 \mathrm{~g} / \mathrm{cm}^{3}$ to be consistent with the undisturbed soil. The remolded soil was wrapped with plastic wrap and placed in a closed thermostat for $24 \mathrm{~h}$ after preparation.

\subsection{Test Plan}

2.4.1. Unloaded Expansion Rate Test. In the unloaded expansion rate test of the paleosol, the related variables of undisturbed soil and remolded soil were consistent, the initial moisture content was set to $10.1 \%, 12.1 \%, 14.1 \%, 16.1 \%$, and $18.1 \%$, and the dry density remained consistent at $1.87 \mathrm{~g} / \mathrm{cm}^{3}$. The prepared ring-shaped sample was placed into the retaining ring of a consolidation container, and then, a guide ring, filter paper, a permeable plate, and a pressurized upper cover were placed on it. Water was poured into the container, and recording of the dial indicator reading was begun, which was taken as $100 \%$ in the initial stage. The rate of change in the submeter was initially fast, and the reading was frequent; as the rate of change of the dial meter decreased, the reading gradually became less frequent until the difference between two readings did not exceed $0.01 \mathrm{~mm}$.

2.4.2. Loaded Expansion Rate Test. First, a permeable stone was placed into the damp soil sample and allowed to stand for $1 \mathrm{~h}$ to make the moisture of the permeable stone consistent with that of the soil sample. The ring-shaped soil sample was placed in the retaining ring of the consolidation instrument; the guide ring, filter paper, and permeable plate were pressed on top, and the cover plate was installed on the instrument so that the dial indicator was in close contact with the center of the cover. The loading lever was adjusted to keep the cover level, $1 \mathrm{kPa}$ was preloaded on the weight plate below to make the test device tightly connected, and the submeter reading was recorded as $100 \%$. The weight plate was used to add the corresponding weight to make the overburden load of the sample reach the set value. At this time, distilled water was slowly added from the bottom to the top in the consolidation instrument, and the liquid level was kept higher than the sample. At the top, dial indicator readings were recorded every $2 \mathrm{~h}$ after immersion until the difference between two adjacent dial indicator readings did not exceed $0.01 \mathrm{~mm}$.

\section{Test Results and Analysis}

3.1. XRD Diffraction Test. The XRD test results of the paleosol were obtained from the research results of other members of my research group [6] (Figure 3). The materials used in the experiment and the material used in this test were from the \#3 tunnel of the Zaosheng section of the Yinxi HSR. According to the test results, the particulate mineral components of the paleosol are quartz, potassium feldspar, calcite, and hematite, with the highest-content-component quartz accounting for $45.4 \%$ of the total content and the lowest-content-component hematite only accounting for $1.0 \%$; the clay mineral components of the paleosol are montmorillonite, illite, and chlorite, with a montmorillonite content of $12.3 \%$, which directly determines the expansion and contraction of the paleosol. According to the determination of the free expansion rate of the paleosol and mineral composition analysis, the free expansion rate is $55 \%$, and the content of montmorillonite is $12.3 \%$. Based on the test results and the definition and quantitative judgment of expansive soil according to the relevant standard, which is based on the free expansion rate, montmorillonite content, and cation exchange amount, the paleosol is weakly expansive soil.

3.2. EDX Test. According to the EDX results of the soil in Figure 4, and element mapping of a paleosol sample using EDX in Figure 5, all the elements are distributed at the six measurement points, with large $\mathrm{Al}, \mathrm{Si}, \mathrm{Ca}$, and Fe peaks (Table 4); the $\mathrm{O}$ content is higher than the actual results due to the influence of oxygen in the environment. $\mathrm{Mg}$ is an important constituent of montmorillonite $\left[(\mathrm{Na}, \mathrm{Ca})_{0.33}(\mathrm{Al}, \mathrm{Mg})_{2}\left(\mathrm{Si}_{4} \mathrm{O}_{10}\right)\right.$ $\left.(\mathrm{OH})_{2} \cdot \mathrm{nH}_{2} \mathrm{O}\right]$, chlorite $\left(\mathrm{Mg}_{9.17} \mathrm{Fe}_{1.02} \mathrm{Al}_{3.46} \mathrm{Si}_{6.35} \mathrm{O}_{36.00}\right)$, and other important constituent elements of minerals, which are cemented with microcrystalline calcium carbonate and quartz particles to form cohesive aggregates. In addition, the calcite $\left(\mathrm{CaCO}_{3}\right)$ content in the paleosol is high, which mainly comes from the large concentration of calcite minerals in the soil, consistent with the large amount of calcareous nodules in the paleosol. The high contents of $\mathrm{MgO}, \mathrm{K}_{2} \mathrm{O}$, and $\mathrm{CaO}$ alkali metals in the soil also indicate that the expansive soil is not chemically weathered to a large extent. Under certain external conditions, if the soil is slightly acidic and humid, then the calcite minerals in the soil will be further decomposed by leaching, loss, and transformation, and the illite minerals containing $\mathrm{K}$ may be transformed into montmorillonite minerals, thus increasing the expansive property of the paleosol, which may lead to deterioration of the project in severe cases.

3.3. NMR Tests. The paleosol $T_{2}$ spectra based on NMR results are shown in Figure 6 . The shapes of the $T_{2}$ distribution curves of the undisturbed soil and the remolded soil are similar, and both are composed of three peaks, but the relaxation times corresponding to the peaks are different. The main peak of the undisturbed soil is mainly distributed in $0.08 \mathrm{~ms}-2.96 \mathrm{~ms}$, and the apex is at $0.742 \mathrm{~ms}$. The main peak of the remolded soil is mainly distributed in $0.09 \mathrm{~ms}-2.96 \mathrm{~ms}$, and the apex is at $0.690 \mathrm{~ms}$. The time distributions of the second main peaks have little difference. Comparing the curves of undisturbed soil and remolded soil, the first peak of remolded soil is significantly larger than that 


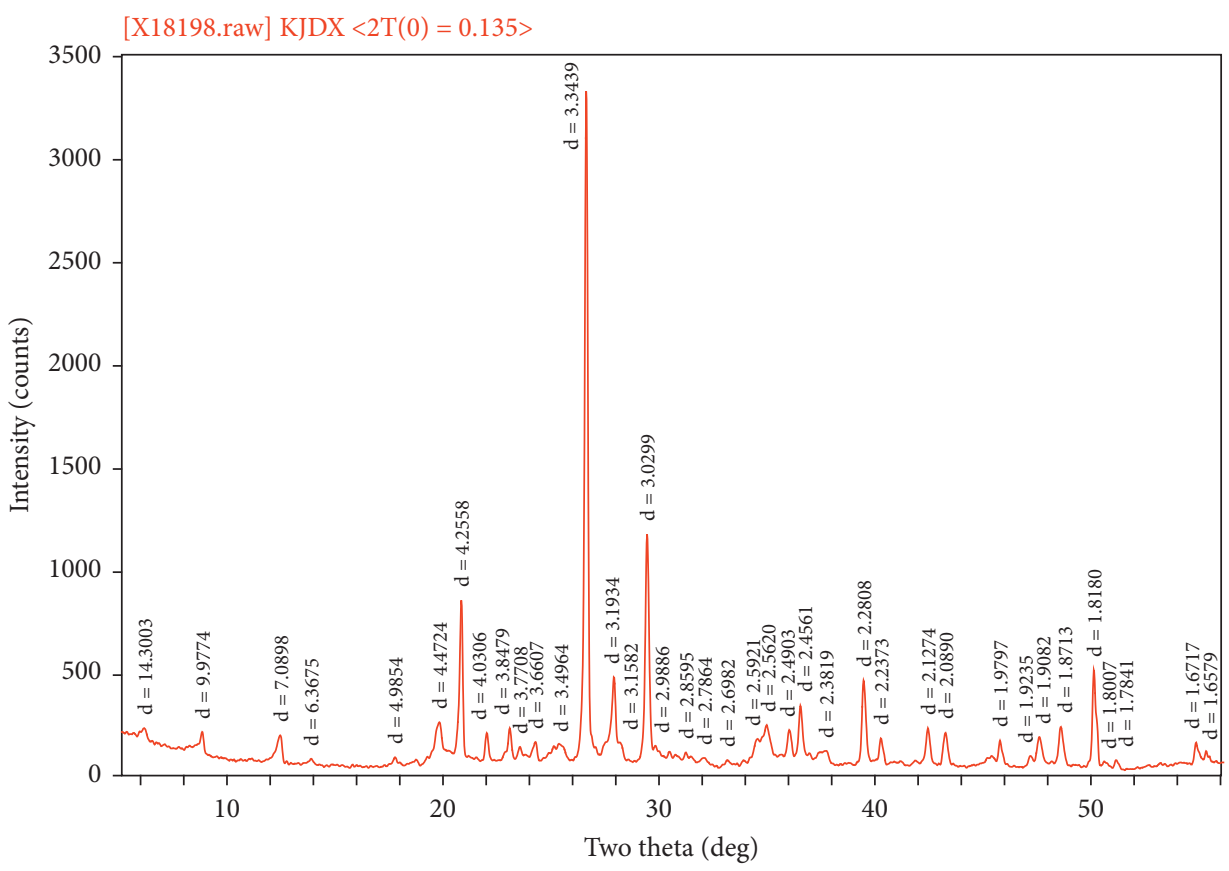

FIgURE 3: XRD results [6].

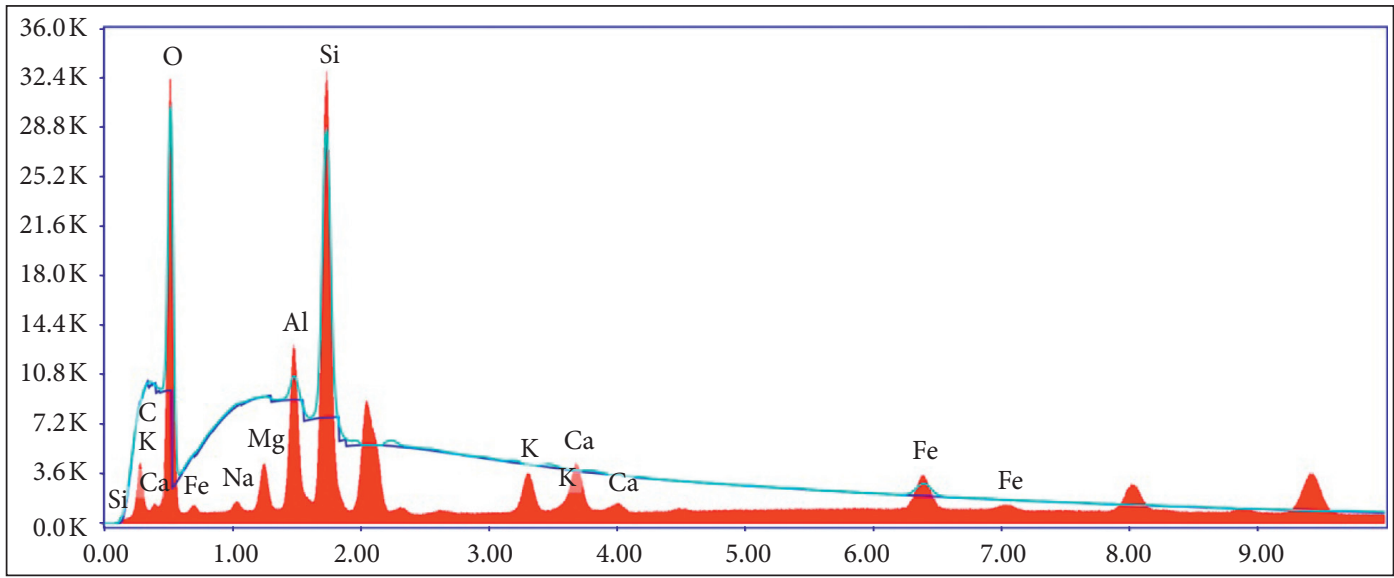

Lsec: 327.7 0 Cnts $0.000 \mathrm{keV}$ Det: Octane Elect Plus

FIGURE 4: EDX spectrum of paleosol samples.

of undisturbed soil, while the differences between the second and third peaks are small.

Paleosol $T_{2}$ curve distribution diagrams can be used to visualize the total pore content within soil, but a better understanding of the internal microstructure of the soil requires quantification of pores of different sizes. According to Liu Yongjian's method of dividing soil pores [27], the pores of soil can be divided into small pores $(r<1 \mu \mathrm{m})$, medium pores $(1 \mu \mathrm{m}<r \leq 20 \mu \mathrm{m})$, large pores $(20 \mu \mathrm{m}<r \leq 1000 \mu \mathrm{m})$, and superlarge pores $(1000 \mu \mathrm{m}<r \leq 3000 \mu \mathrm{m})$ based on the pore size. According to the calculation results of formula (2), as shown in Figure 7, the pore distributions in the undisturbed soil and remolded soil mainly include medium pores, accounting for $88 \%-91 \%$ of the total pores, followed by large pores, accounting for $6 \%-8 \%$ of the total pores, while the contents of small pores and superlarge pores are very small; the difference in the pore size distributions of the undisturbed soil and remolded soil is small. From the distribution of small pores and medium pores, the proportion of medium pores in the total pores after remolding of the soil is somewhat increased, the proportions of large pores and superlarge pores are slightly lower than those in the undisturbed soil, and the proportion of small pores is basically unchanged.

An analysis of the reasons shows that the number of pores in the soil increases after remolding, and water is more likely to infiltrate the soil. When immersed in water, the clay minerals in the soil contact more water, and the clay minerals expand, reducing the diameters of the soil macropores. The macropores are extruded into multiple small pores. Because the soil sample needs to be saturated before the NMR test, the proportions of large pores and superlarge pores in the remolded soil are smaller than that in the undisturbed soil. 

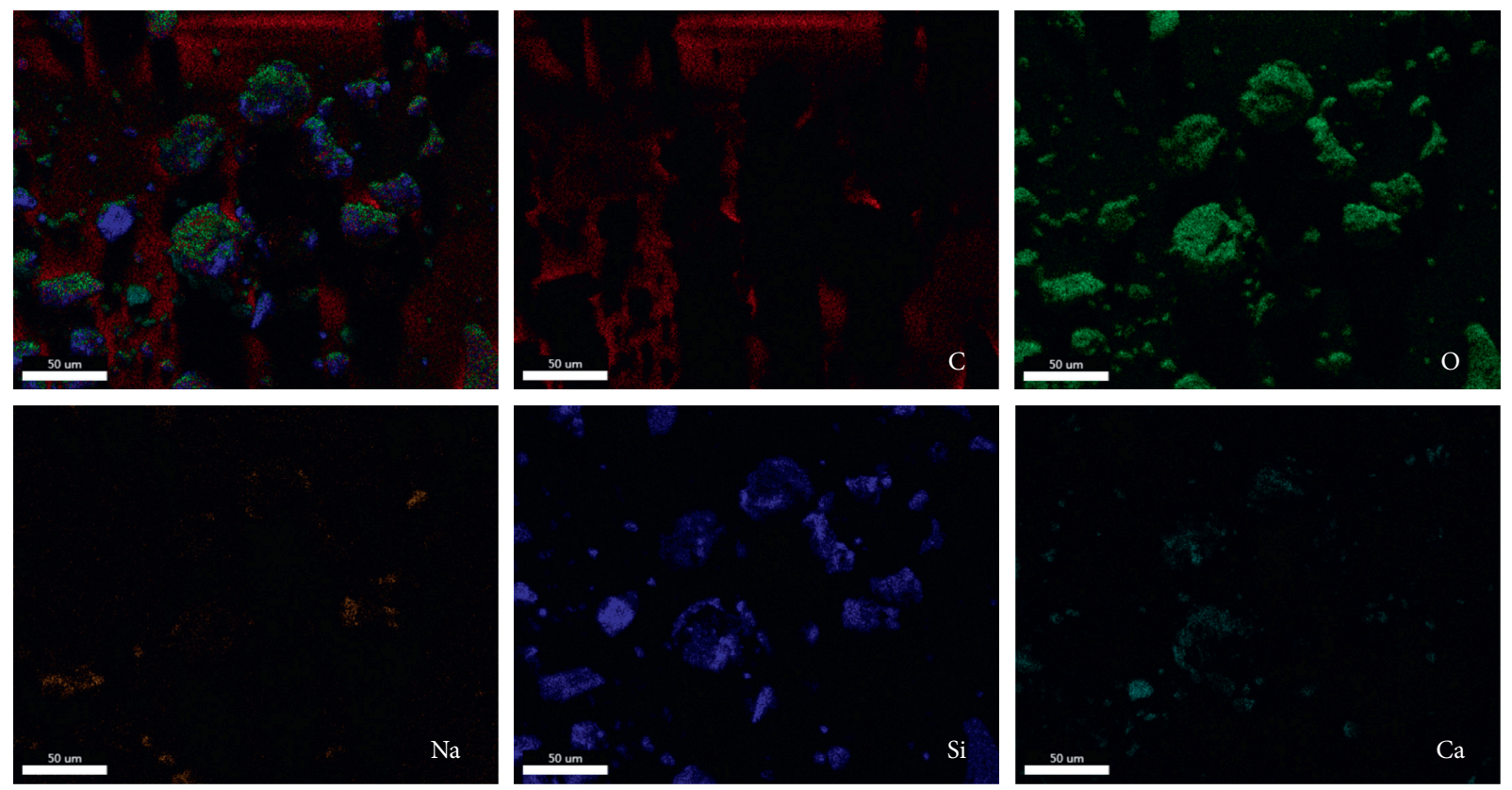

FIGURE 5: Element mapping of a paleosol sample using EDX.

TABle 4: Percentage of elements in the paleosol.

\begin{tabular}{lccccccccc}
\hline Serial & \multicolumn{8}{c}{ Elemental distribution-atomic percentages (\%) } \\
number & $\mathrm{C}$ & $\mathrm{O}$ & $\mathrm{Na}$ & $\mathrm{Mg}$ & $\mathrm{Al}$ & $\mathrm{Si}$ & $\mathrm{K}$ & $\mathrm{Ca}$ & $\mathrm{Fe}$ \\
\hline 1 & 0.03 & 44.56 & 0.13 & 0.09 & 4.02 & 35.02 & 0.31 & 1.34 & 14.50 \\
2 & 0.02 & 33.19 & 0.07 & 1.30 & 9.13 & 39.60 & 5.43 & 2.64 & 8.61 \\
3 & 1.00 & 17.05 & 0.11 & 0.65 & 2.54 & 5.78 & 2.77 & 30.23 & 39.87 \\
4 & 5.01 & 45.12 & 0.10 & 2.89 & 9.89 & 21.37 & 3.77 & 3.65 & 8.20 \\
5 & 65.37 & 25.31 & 0.57 & 0.07 & 1.35 & 3.51 & 0.66 & 1.59 & 1.58 \\
6 & 6.93 & 31.82 & 0.30 & 1.65 & 6.42 & 13.73 & 2.44 & 8.87 & 27.85 \\
\hline
\end{tabular}

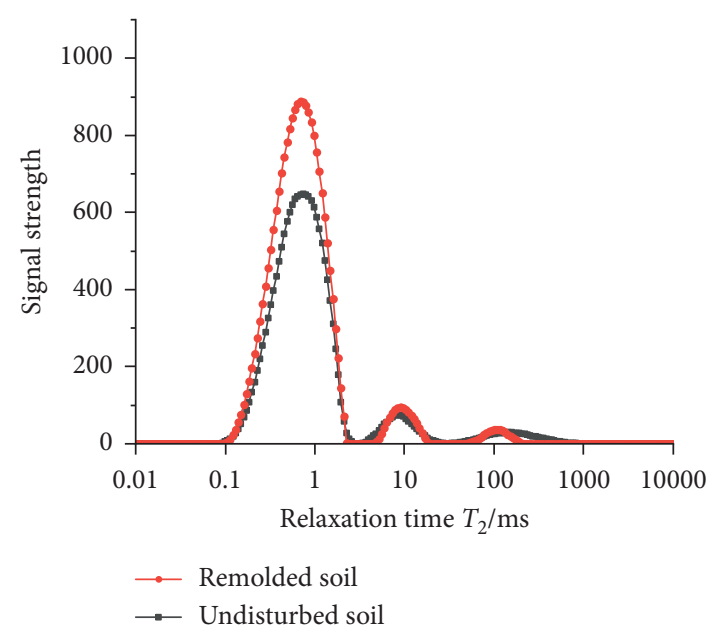

FIgURE 6: $(\mathrm{T})_{2}$ spectra of the paleosol.

3.4. SEM Test. Due to space limitations, the presented results of the SEM experiment only include SEM images of undisturbed soil and remolded soil with a soil moisture content of $14.1 \%$ (natural moisture content). To obtain a clear understanding of the soil microstructure, magnification was used in this qualitative analysis. The $5000 \mathrm{x}$

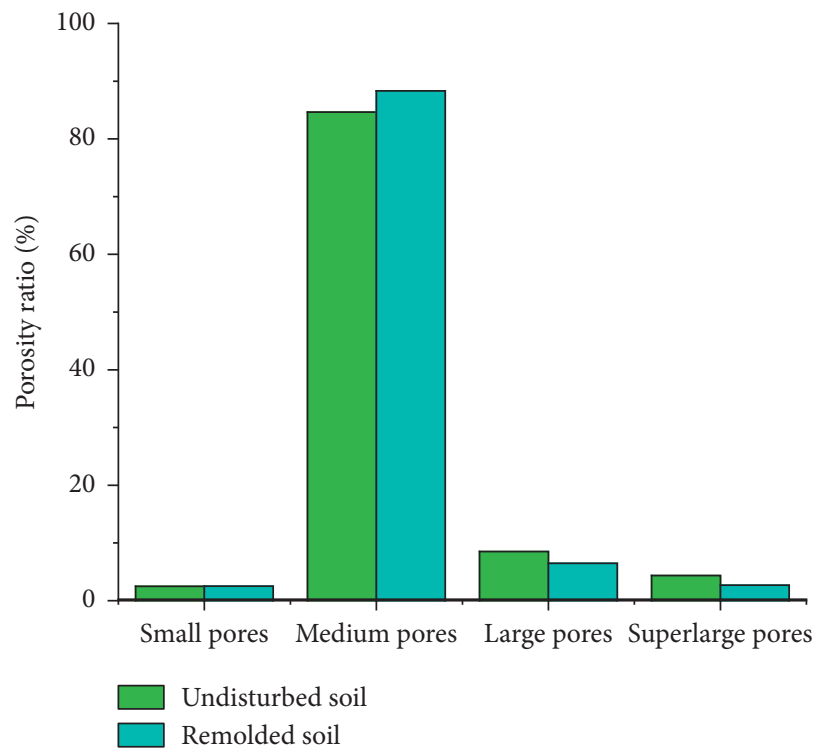

Figure 7: Paleosol pore fractions.

SEM images can enable the microscopic particles and pore structure of the soil to be clearly distinguished. The results are shown in Figures 8 and 9. The basic unit bodies of the undisturbed soil include detritus particle, superimposed, and aggregate units. The detritus particle units are mainly angular and semicircular abrasive particles, and the contact forms are mainly "point-point" and "point-surface." This kind of particle does not have strong expansion characteristics. The superimposed units are mainly flat particles and flake particles, which are formed by "face-face" and "face-edge" superimposition. This is the main contact form between the undisturbed soil particles. These units are the basic unit with expansion 

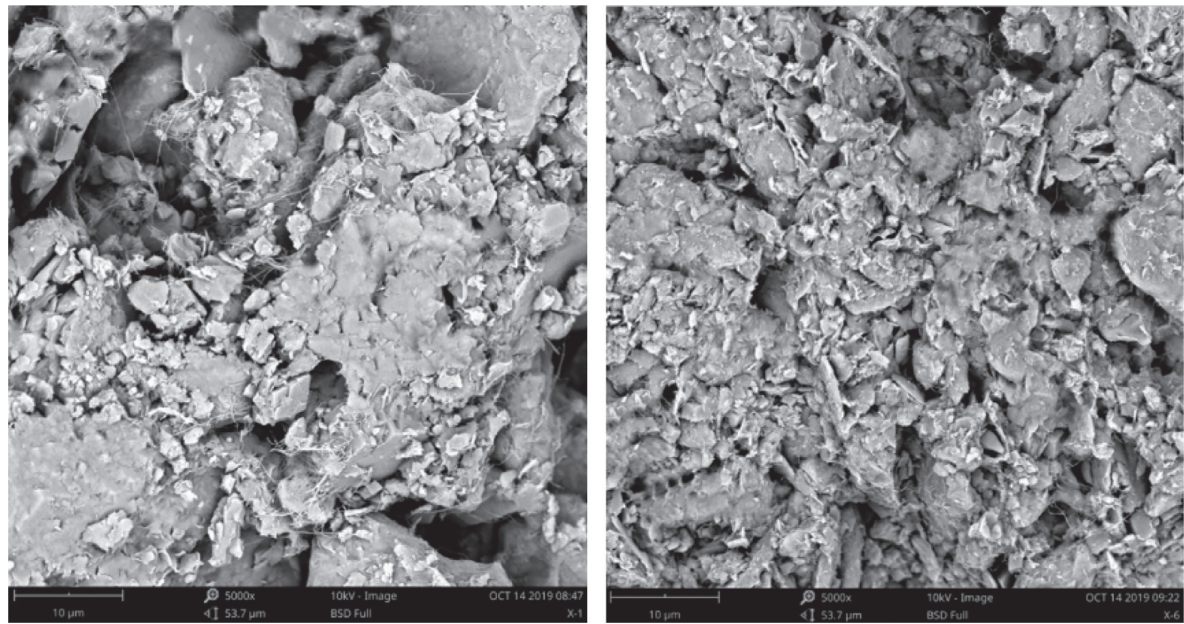

FIGURE 8: SEM photos of undisturbed soil.
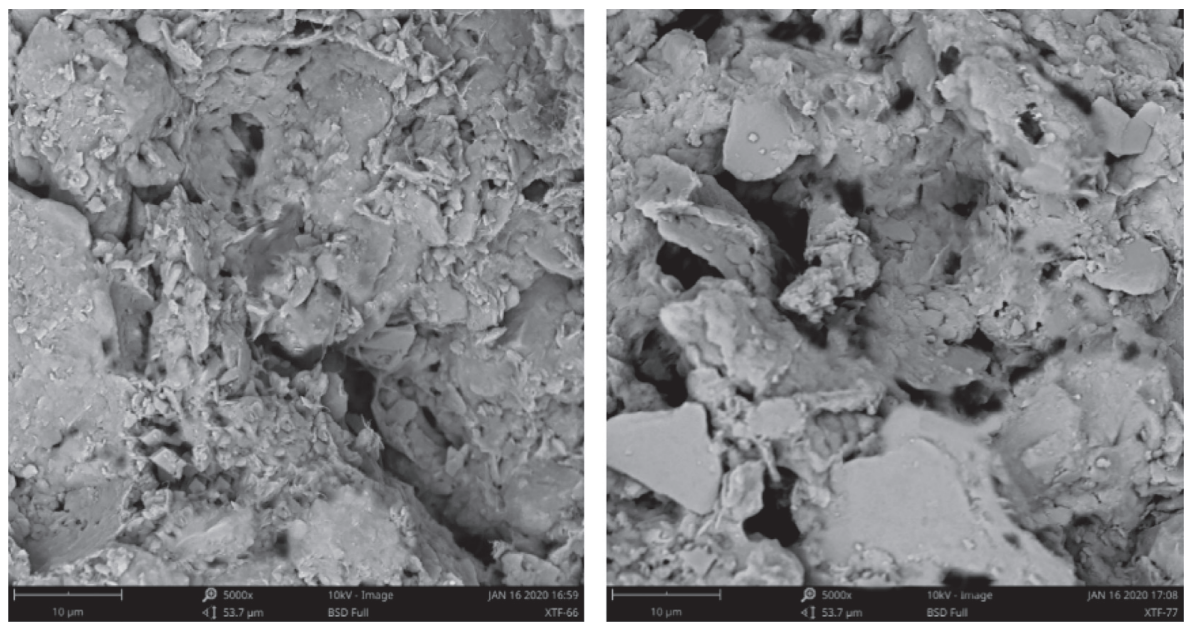

FIGURE 9: SEM photos of remolded soil.

characteristics. Aggregate units are mainly formed by the cementation of round abrasive particles with flat particles and flaky particles, which are aggregated in the "face-toface" form. Aggregate units can also cause soil expansion. When the soil particles are broken and compacted to become remolded soil, the granular particles first become larger aggregates and then gradually break down and become smaller particles. The soil particles obtained in the remolded soil sample fabrication process are more uniform, and a large number of tiny pores and microcracks exist between the soil particles. Under water immersion, the montmorillonite, illite, and other mineral components contained in the clay tablets, especially for "surface surface" and "surface - edge" arrangements of the clay tablets, absorb water and expand, and the water film thickens as time elapses. The overhead pores collapse and both the particles and pore morphology change when the contact between soil particles is mostly "point-to-point" and "point-to-face" contact.

To better distinguish the morphological characteristics of soil particles in the paleosol under undisturbed and remolded conditions, the dimensionless particle abundance $C$ is introduced, which is calculated as follows:

$$
C=\frac{L}{B} \text {. }
$$

In the formula, $B$ is the length of the short axis of the particles, $L$ is the length of the long axis of the particles, and the value of $C$ ranges from 0 to 1 ; a value approaching 0 indicates that the soil particles are more flat in shape, whereas a value approaching 1 indicates that the particle shape tends toward round.

The particle abundance of undisturbed soil and remolded soil is shown in Figures 10 and 11. The particle abundance of the undisturbed and remolded paleosol under different water contents is distributed in each interval, with a larger percentage of $0.5-0.8$, indicating that the shape of the paleosol particle units mainly tends to be flat or less round, elongated, and round. Among them, the percentage of particle abundance in the $0-0.1$ range is significantly greater for the remolded soil than for the undisturbed soil, while the percentage of abundance in the 0.6-0.7 range is lower for 


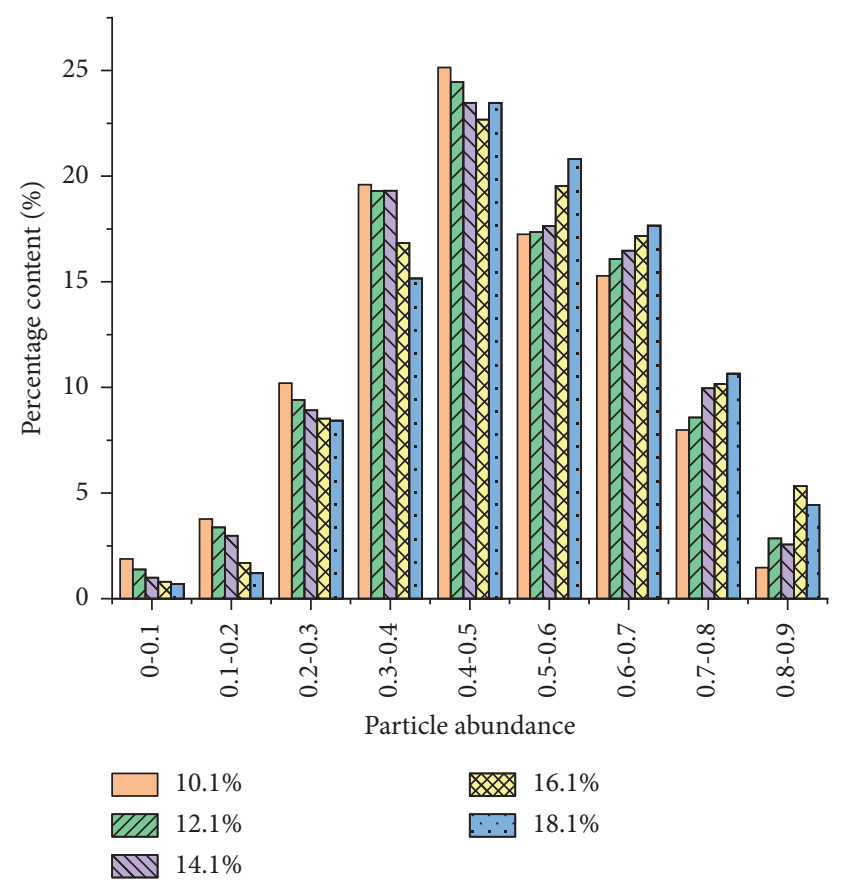

FIgURE 10: Abundance percentage content of undisturbed soil particles.

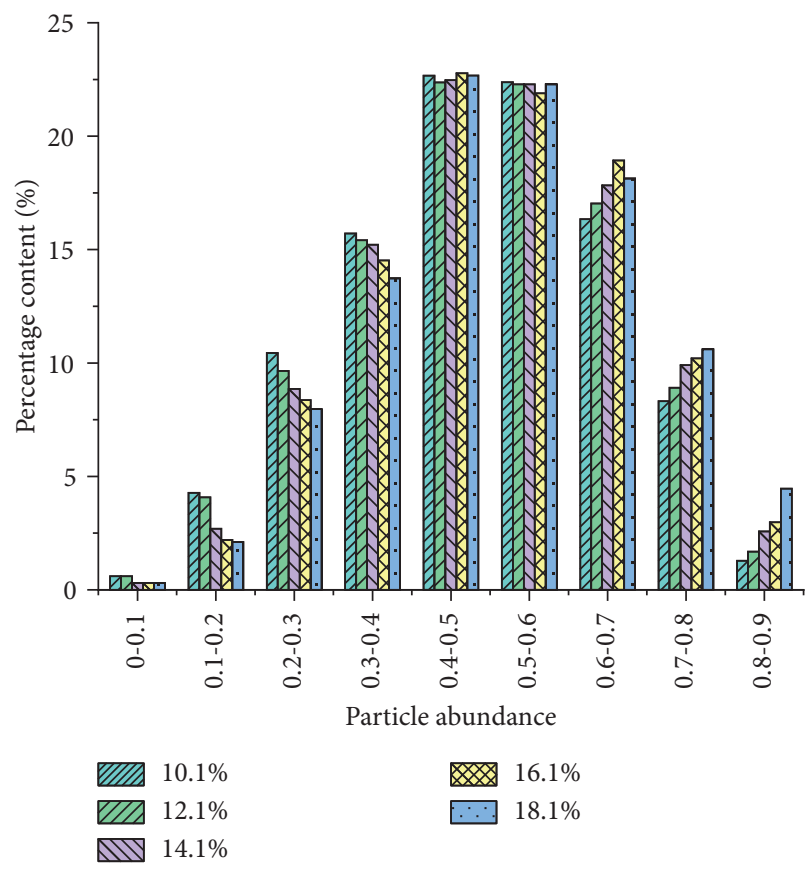

FIgURE 11: Abundance percentage content of remolded soil particles.

remolded soil particles than for the undisturbed soil. The cause of this phenomenon is the process of fracture and remolding of the soil. The external force causes the roughly elliptical particles in the undisturbed soil to break and disintegrate into irregular flat fine particles, thus causing the percentage of remolded soil particles with abundance in the $0.6-0.7$ range to decrease and in the $0-0.1$ range to increase.
The particle abundance for different moisture contents of the undisturbed soil is basically flat in the range of $0.4-0.5$ and $0.5-0.6$, indicating that the soil particles with shapes between the round and strip shapes have a strong adhesive force, the interaction between the particles is more stable, and an increase in the soil moisture will not cause destruction of the original cementation state between the particles. This range of particle abundance accounts for the most among the soil mass, creating the fundamental internal conditions for expansion. The particle abundance percentage in the same abundance interval with 0.5 as the upper limit decreases and then increases with increasing moisture content for both the undisturbed and remolded soils, which indicates that the long-strip soils are less stable than the round type and more prone to structural changes under the disturbance of external conditions.

\subsection{Expansion Rate Test}

3.5.1. Unloaded Expansion Rate Test. The relationship curves of the unloaded expansion rate of undisturbed soil and remolded soil with time are shown in Figures 12 and 13. The unloaded expansion rate curves of the two soils can be divided into three phases. During the rapid expansion stage of $0-1 \mathrm{~h}$, the slope of the curve is the largest, and the expansion rate increases the fastest. The soil expands by absorbing water, and the hydrophilic mineral components are in full contact with water and produce vertical deformation under the confined conditions. The expansion deformation is extremely significant; the expansion rate in this stage accounts for more than half of the total expansion rate, and the lower the initial water content is, the more pronounced the increase in the soil expansion rate is, indicating that the unloaded expansion rate of the soil is negatively correlated with the water content. During the 1-12 h slow expansion stage, the slope of the curve decreases compared with the previous stage, indicating that the growth rate of the expansion rate decreases. With the continuous infiltration of water, due to the hydrophilicity around the pores of the soil sample, the mineral and water basically react completely, the water absorption capacity of the sample is weakened, the water continues to diffuse into the soil sample, and the expansion rate slows down; the expansion rate in this stage accounts for approximately $20 \%$ of the total expansion rate. In the stable stage of $12-40 \mathrm{~h}$, the curve is approximately straight and horizontal, and the expansion rate is extremely small, accounting for approximately $5 \%$ of the total expansion rate. During this stage, the expansion potential energy of the sample is basically released, and the vertical deformation of the sample is basically stable, which lasts for a long time. As the initial moisture content of the sample increases, the soil takes longer to swell to stabilization, which has a significant impact on the size of the unloaded expansion rate. Compared with the undisturbed soil, the unloaded expansion curve of the remolded soil can also be divided into three identical stages. In the first stage at the same moisture content, the expansion rate of the remolded soil is approximately 3 times that of the undisturbed soil and 


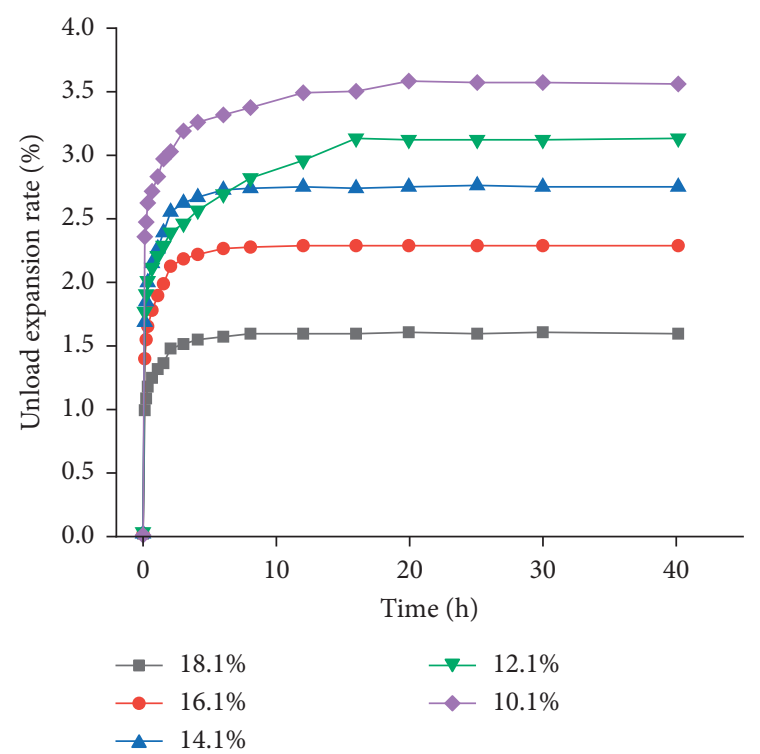

FIGURE 12: Time variation curve of the unloaded expansion rate of undisturbed soil.

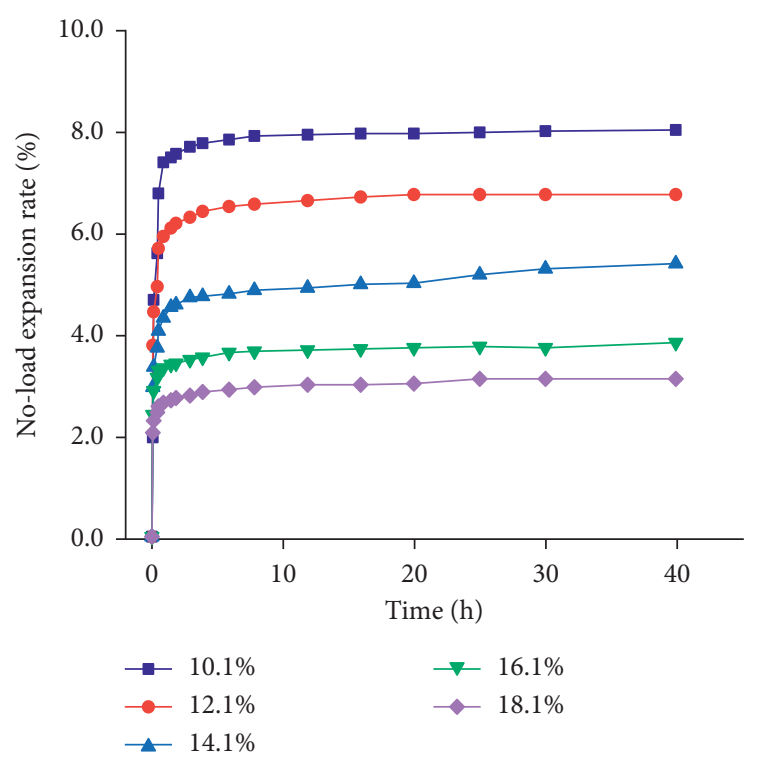

FIGURE 13: Time variation curve of the unloaded expansion of remolded soil.

even higher than the final expansion rate of the undisturbed soil. In the second stage, the expansion rate of the remolded soil is $15 \%$ of the total expansion rate. In the third stage, the expansion potential energy of the specimen is almost completely released, and the vertical deformation of the specimen becomes stable, which lasts for a long time. The final expansion rate of the remolded soil is approximately 2 times that of the undisturbed soil.

Figures 14 and 15 show that the loaded expansion rate of the remolded soil is obviously greater than that of the undisturbed soil, and the curves of the two are consistent. Under the same overburden load condition, the load expansion rate decreases with increasing initial moisture

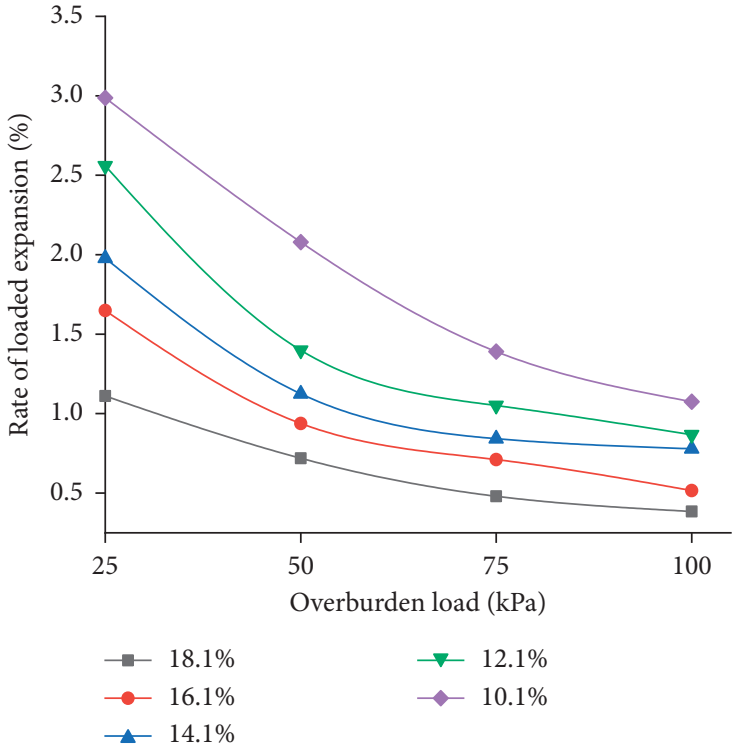

Figure 14: Curve of the loaded expansion rate of undisturbed soil.

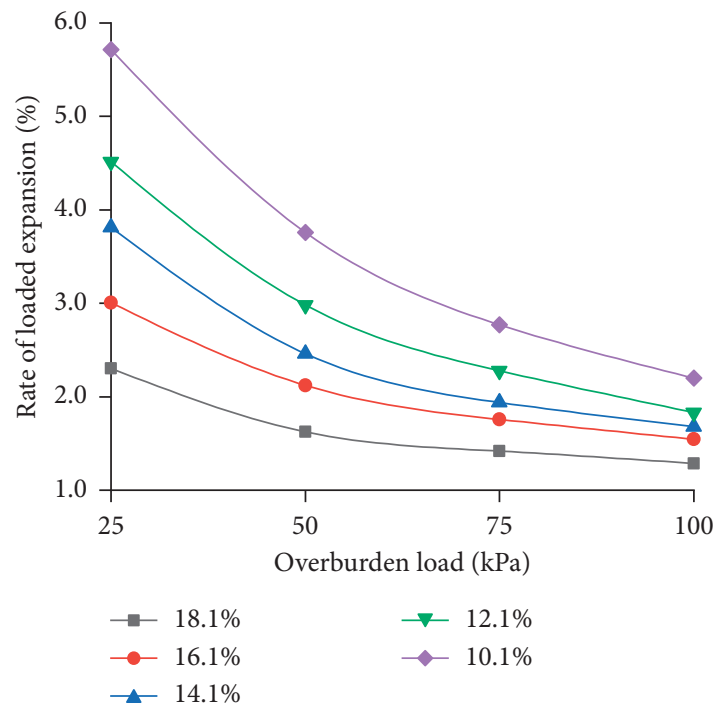

FIGURE 15: Curve of the loaded expansion rate of remolded soil.

content. When the overburden load is $25 \mathrm{kPa}$, the load expansion rate reaches the maximum value. For soils with initial moisture contents of $10.1 \%, 12.1 \%, 14.1 \%, 16.1 \%$, and $18.1 \%$, their load expansion rates are $5.7 \%, 4.5 \%, 3.8 \%, 2.9 \%$, and $2.3 \%$, respectively; the downward trend of the load expansion rate curve decreases with increasing overburden load. The difference between the loaded expansion rates for different initial moisture content under the same overburden load condition decreases with increasing overburden load. The lower the initial moisture content is, the greater the reduction in the loaded expansion rate is. The reason for this result is that, under the action of the overburden load, the expansion and deformation of the paleosol are obviously suppressed because under the same initial moisture content and dry density, on the one hand, an increase in the overburden load reduces the rate of water diffusion into the 
soil and; on the other hand, as the overburden load increases, the effective stress inside the soil increases. The thickening of the combined water film on the surface of clay minerals is suppressed, which reduces the expansion and deformation of the soil. When the initial moisture content is low, the overburden load has an obvious inhibitory effect on the loaded expansion rate. As the initial moisture content increases, the inhibitory effect decreases. Comparing the undisturbed soil and the remolded soil, the overburden load has a lower inhibitory effect on the remolded soil than on the undisturbed soil.

\section{Conclusions}

This paper takes the paleosol in the tunnel as the research object, comprehensively analyzes the microstructure of the paleosol from the mineral composition, formation elements, pore structure, and particle morphology and conducts related experiments on the expansion characteristics. The causes of the expansion of paleosol are further explained from micro- and macroaspects. The main findings of this research are as follows:

(1) The mineral components of the paleosol are mainly quartz, potash feldspar, calcite, and hematite, with the highest-content-component quartz accounting for $45.4 \%$ of the total content; the clay mineral composition of the paleosol has the highest content of montmorillonite at $12.3 \%$, which also directly determines the expansion of the paleosol. In terms of elemental composition, the elemental composition of the paleosol is dominated by $\mathrm{Al}, \mathrm{Si}, \mathrm{Ca}$, and $\mathrm{Fe}$, which are the constituent elements of mineral components such as quartz, calcite, and montmorillonite, which creates the inherent conditions for the expansion of the paleosol.

(2) The $T_{2}$ distribution curves of the undisturbed and remolded paleosol are composed of three peaks: one main peak and two secondary peaks. The pore distribution mainly includes medium pores, followed by large pores, and the contents of small pores and superlarge pores are very small. In terms of particle contact mode, the undisturbed soil is mostly in the form of "face-to-face" and "face-to-edge" contact. "Point-to-surface" and "point-to-point" contacts are the main forms of contact for remolding soil.

(3) In terms of particle abundance, the undisturbed and remolded paleosol particle abundances were distributed across all intervals, with higher percentages between 0.5 and 0.8 , indicating that the morphology of paleosol particle units tends to be oblate or similar to round, elongated, and less round. The difference between the two soils is that the undisturbed soil has a higher content of round-like particles, whereas the remolded soil has a higher content of long-strip particles.

(4) The unloaded expansion rate change curves of the undisturbed soil and remolded soil both go through three stages. As time elapses, the unloaded expansion rate of the remolded soil in each stage is significantly greater than that of the undisturbed soil. The final expansion rate is approximately twice that of the undisturbed soil. The loaded expansion rates for both the undisturbed soil and the remolded soil decrease with increasing overburden load.

\section{Data Availability}

The data used to support the findings of this study have not been made available because the experimental data involved in the paper are all obtained based on our own designed experiments and need to be kept confidential; we are still using the data for further research.

\section{Conflicts of Interest}

The authors declare that they have no conflicts of interest.

\section{Acknowledgments}

This work was supported by the National Natural Science Foundation of China (Grant no. 42072319) and 2017 Shaanxi Province Key R\&D Program Projects (Grant no. 2017ZDXM-SF-082).

\section{References}

[1] Z.-D. Feng, H. B. Wang, C. Olson et al., "Chronological discord between the last interglacial paleosol (S1) and its parent material in the Chinese Loess Plateau," Quaternary International, vol. 117, no. 1, pp. 17-26, 2004.

[2] G. Steven and J. Lincoln, "Paleopedology and paleoclimatic implications of late ordovician vertic paleosols, juniata formation, southern appalachians," Journal of Sedimentary Research, vol. 62, 1992.

[3] H. Zheng, B. Theng, and J. S. Whitton, "Mineral composition of loess-paleosol in the loess plateau of China and its environmental implications," Chinese Journal of Geochemistry, vol. S1, pp. 113-123, 1993.

[4] H. Zheng, B. K. G. Theng, and J. S. Whitton, "Mineral composition of Loess-Paleosol samples from the Loess Plateau of China and its environmental significance," Chinese Journal of Geochemistry, vol. 13, no. 1, pp. 61-72, 1994.

[5] M. Wieder and G. Gvirtzman, "Micromorphological indications on the nature of the Late Quaternary Paleosols in the southern coastal plain of Israel," Catena, vol. 35, no. 2-4, pp. 219-237, 1999.

[6] W. Ye, Y. Wu, and G. Yang, "Study on microstructure and macro-mechanical properties of paleosol under dry-wet cycles," Chinese Journal of Rock Mechanics and Engineering, vol. 38, pp. 2162-2137, 2019.

[7] Y. Wu, W. Ye, and G. Yang, "Experimental research on micropore and macro-deformation characteristics of soils considering stress paths," Chinese Journal of Rock Mechanics and Engineering, vol. 38, pp. 2311-2320, 2019.

[8] N. Wang, X. Liu, Y. Xue, and X. Jiao, "Test of dynamic strength characteristics of paleosol," Advanced Materials Research, vol. 690-693, pp. 747-751, 2013.

[9] H. Bayesteh and A. A. Mirghasemi, "Numerical simulation of pore fluid characteristic effect on the volume change behavior 
of montmorillonite clays," Computers and Geotechnics, vol. 48, pp. 146-155, 2013.

[10] D. Terzis and L. Laloui, "3-D micro-architecture and mechanical response of soil cemented via microbial-induced calcite precipitation," Scientific Reports, vol. 8, p. 1416, 2018.

[11] M. Jiang, T. Li, C. Thornton et al., "Wetting-induced collapse behavior of unsaturated and structural loess under biaxial tests using distinct element method," International Journal of Geomechanics (ASCE), vol. 17, pp. 0601-6010, 2016.

[12] Z. Shen and M. Jiang, "DEM simulation of bonded granular material. Part II: extension to grain-coating type methane hydrate bearing sand," Computers and Geotechnics, vol. 75, pp. 225-243, 2016.

[13] S. K. Sahoo, B. N. Madhusudhan, H. North et al., "Laboratory insights into the effect of sediment-hosted methane hydrate morphology on elastic wave velocity from time-lapse 4-D synchrotron X-ray computed tomography," Geochemistry, Geophysics, Geosystems, vol. 19, no. 11, pp. 4502-4521, 2018.

[14] M. Hyodo, J. Yoneda, N. Yoshimoto, and Y. Nakata, "Mechanical and dissociation properties of methane hydratebearing sand in deep seabed," Soils and Foundations, vol. 53, no. 2, pp. 299-314, 2013.

[15] M. Jiang, Z. Yin, and Z. Shen, "Shear band formation in lunar regolith by discrete element analyses," Granular Matter, vol. 18, no. 32, pp. 4-14, 2016.

[16] M. Jiang, Y. Dai, L. Cui et al., "Experimental and DEM analyses on wheel-soil interaction," Journal of Terramechanics, vol. 76, pp. 15-28, 2017.

[17] A. N. Chiaramonti, J. D. Goguen, and E. J. Garboczi, "Quantifying the 3-dimensional shape of lunar regolith particles using X-ray computed tomography and scanning electron microscopy at sub- $\gamma$ resolution," Microscopy and Microanalysis, vol. 23, no. S1, pp. 2194-2195, 2017.

[18] M. Andy, P. Trevor, J. Burke, J. Neal, and K. Bruce, "In situ nuclear magnetic resonance response of permafrost and active layer soil in boreal and tundra ecosystems," The Cryosphere, vol. 11, pp. 294-2955, 2017.

[19] S. Costabel, C. Weidner, M. Müller-Petke, and G. Houben, "Hydraulic characterisation of iron-oxide-coated sand and gravel based on nuclear magnetic resonance relaxation mode analyses," Hydrology and Earth System Sciences, vol. 22, no. 3, pp. 1713-1729, 2018.

[20] Valori, B. Andrea, T. Mohammed, and Reza, Nuclear Magnetic Resonance (NMR) Distributions and Pore Information, United States Patent, Sugar Land, TX, USA, 2019.

[21] H. Thomas and K. Norbert, "Joint inversion of nuclear magnetic resonance data from partially saturated rocks using a triangular pore model," Geophysics, vol. 83, pp. 15-28, 2018.

[22] S. Tao, S. Chen, D. Tang, X. Zhao, H. Xu, and S. Li, "Material composition, pore structure and adsorption capacity of lowrank coals around the first coalification jump: a case of eastern Junggar Basin, China," Fuel, vol. 211, pp. 804-815, 2018.

[23] A. Stephanie, A. Edward, M. Daniel, E. Alexis, and K. Kubanek, "Characterizing Paleosols by reflectance spectroscopy, raman spectroscopy, and X-ray diffraction," in Proceedings of the 54th Annual GSA North-Central Section Meeting, Duluth, Minnesota, May 2020.

[24] C. Won, H. Hong, F. Cheng et al., "Clay mineralogy and its palaeoclimatic significance in the Luochuan loess-palaeosols over $1.3 \mathrm{Ma}$, Shaanxi, northwestern China," Frontiers of Earth Science, vol. 12, pp. 1-14, 2017.

[25] J. Meng and X.-A. Li, "'Effects of carbonate on the structure and properties of loess and the corresponding mechanism: an experimental study of the Malan loess, Xi'an area, China,"
Bulletin of Engineering Geology and the Environment, vol. 78, no. 7, pp. 4965-4976, 2019.

[26] M. Dalhat, B. Alaadin, and M. Khaled, "Effect of montmorillonite content in natural Saudi Arabian clay from Al-Hassa city on its adsorptive performance for single aqueous uptake of $\mathrm{Cu}$ (II) and $\mathrm{Ni}$ (II)," Journal of King Saud University-Science, vol. 32, pp. 412-422, 2020.

[27] Y. Liu, Z. Li, and L. Guo, "Pore characteristics of soft soil under triaxial shearing measured with NMR," Chinese Journal of Rock Mechanics and Engineering, vol. 37, pp. 1924-1932, 2018. 